\title{
Predisposing Factors for Dural Tear during Lumbar Spine Surgery
}

\author{
MOHAMED MOHAMED, M.D. and MOHAMED A. HEWEDY, M.D. \\ The Department of Neurosurgery, Faculty of Medicine, Beni-Suef University, Egypt
}

\begin{abstract}
Background: Dural tear is a common complication of lumbar spine surgery. The aim of this prospective study was to identify the predisposing factors for dural tear in lumbar spine surgery.

Patients and Methods: We prospectively recorded data of 174 patients with lumbar spine surgery from 2013 to 2016 in Faculty of Medicine, Bani seuf University. We compared result obtain from the patients in which a dural tear occurred (Group A) and those in which a dural tear did not occur (Group B) excluded criteria are recurrent procedures, and intradural procedures.
\end{abstract}

All the patient data like age, sex clinical examination, and scheduled procedure, and intra-operative data (surgeon experience. Type and time of surgery) were record and compared between the two groups.

Results: 104 patients underwent discectomy, 50 patients underwent laminectomy. And 20 patients underwent lumber fixation. Among the 104 patients who underwent discectomy 5 patients had a dural tear. Among the 50 patients who underwent laminectomy 3 patients had dural tear. Amongthe 20 patient underwent lumber fixation 2 patients had dural tear. Patients with incidental durotomy were older (mean $60 \pm 5$ vs $50 \pm 5$ years), and had longer surgery ( $180 \pm 30$ vs $120 \pm 30$ minutes), compared with the patients without dural tear. The incidence was significantly higher with lumber fixation (prolonged surgery) when physician training was examined; residents were responsible for $50 \%$ of all dural tear.

Conclusion: Predisposing factors for dural tear were, older age, prolonged surgery, and the years of physician training or resident experience appear to be a major risk.

Key Words: Dural tear - Lumbar surgery-Predisposing factors $-C S F$.

\section{Introduction}

ACCIDENTLY intra operative tear of the dura is the commonest complication during lumbar spine surgery $[1,2]$. By reviewing the literature we found various factors affecting the happening of accidental durotomy during lumbar spine procedures, $[3,4]$ in

Correspondence to: Dr. Mohamed Mohamed, E-Mail: shabanneuro@gmail.com many study, the incidence of dural tear was about $16 \%$. They found that age of the patient was a risk factor [5]. However, a history of a lumbar surgery and the duration of the surgeon's training did not affect the incidence although other studies showed a higher occurrence of tears in recurrent spine surgeries, ranging.

From $2.1 \%$ to $15.9 \%,[6-8]$ the previously mentioned studies were retrospective studies and did not compare between affected and non affected people [9-12] if dural tear occurred and not managed in proper way, it can lead to CSF leak or psudomeningeocele $[13,14]$.

The aim of our study was to prospectively determine risk factors for intended durotomies during lumbar spine procedures.

\section{Patients and Methods}

We prospectively recorded data of 174 patients with lumbar spine surgery from March 2013 to March 2016 in Faculty of Medicine. Bani Seuf University. We compared result obtain from the patients in which a dural tear occurred (Group A) and those in which a dural tear did not occur (Group B).

\section{Exclusion criteria:}

1- All patient with recurrent surgeries.

2- All patients with intra dural procedure such as tumors.

3- All patients with traumatic dural tear.

All data are recording such as age, sex, and the indication of the spine surgery in each case, and the number of levels affected in each case the length of surgery (minutes), was also recorded, all these data were compared between patients who had intra operative dural tears and patients who did not have a dural tear. In the cases who suffered 
from accidental intra operative dural tear the rank of the surgeon was documented (resident, assistant lecture or senior staff) also the instrument was used and how it managed intra operatively. We did not document the site of the tear during the post operative period in those who had dural tear; we recorded any headache due csf loss specially on the first day and other complications such as leak or pseudo meningiocele and the management of complications.

\section{Results}

In this study we documented the data of 174 patients underwent various degenerative lumbar procedures 104 patients of them underwent discectomy, 50 patients underwent laminectomy. And 20 patients underwent lumber fixation the total number of patients who had dural tear was $10(5.74 \%)$ patients and their distribution between the different procedures was. Out the 104 patients who underwent discectomy 5 (4.8\%) patients had a dural tear. Out the 50 patients who underwent laminectomy $3(6 \%)$ patients had dural tear. And out of the 20 patient underwent lumber fixation $2(10 \%)$ patients had dural tear. Out of these 10 patients with dural tear $6(60 \%)$ patient were females the mean age in patients with accidental durotomy was $60 \pm 5 y$, and the mean age in the non affected group was $50 \pm 5$ years so the dural tear group was older the mean surgical time in the accidental tear group was $180 \pm 30$ minutes while the mean surgical time in the other group was $120 \pm 30$ minutes so dural tear happened more in the longer surgery and also lumbar fixation was the highest incidence of dural tear, patients considering surgical experience and its relation with the durotomy resident were responsible for $50 \%$ of cases. Accidental tear occurred in 4 cases with dissector usage, and in 6 cases because of a kerrison. In $7(70 \%)$ of the 10 cases of accidental dural tear, primary repair with 3-0 vicryle suture was the management, the other 3 patient of the tear was small or could not sutured so sheet of fat graft was used to close the tear. In the follow-up period, only 2 cases with dural tear complain from headache specially on first day of surgery.

Table (1): Number of disease in the study.

Table (2): Icedance of CSF leak in the study.

\begin{tabular}{lclcc}
\hline Disease & Number & Disease & Number & Incidence \\
\hline Lumbar disc prolaps & 104 & Lumbar disc prolaps & 5 & $4.8 \%$ \\
Lumbar Canal stenosise & 50 & Lumbar Canal stenosise & 3 & $6 \%$ \\
Spodylolisthesis & 20 & Spodylolisthesis & 2 & $10 \%$ \\
\hline
\end{tabular}

\section{Discussion}

In this prospective study, all data for patients who underwent lumbar surgery are collected to detect the incidence and predisposing factors for accidental dural tear. The incidence of unintended durotomy was range from $0.5 \%$ to $18 \%$, such a big wide Range is due do multicenter studies, Wang et al., found a $14 \%$ incidence of dural tears [8]. Sin et al., found a $10 \%$ incidence of a dural tear in a 76 patients who underwent lumbar spine surgery for degenerative spine [10]. In the study conducted by Yoshimasa et al., the incidence was 4\% [14] the incidence in our study was (5.7\%) Epstein in his study reported that patients without dural tear were younger than those with dural tear (average age 69 vs. 74 years, respectively) [12]. We obtained similar results in our study (average age 50 vs. 60 years, respectively. The incidence of dural tear in our study was higher in females $(60 \%)$ than males also more common in old age due to Degenerative changes such as (narrowing of the spinal canal, and thicker ligamentum flavum) Yoshimasa et al., reported that in patients with canal stenosis only the rate was $13 \%$ [14]. Our study found that the rate of dural tear was significantly higher in patients with degenerative spondylolisthesis (during lumbar fixation) $(10 \%)$ than in those with other lumbar disorder. This higher incidence is a result from severe degenerative and adhesive changes around the lesion. In our study we had 2 cases suffered from csf leak they were managed with secondary sutures and frequent dressing with antibiotic coverage and we did not had any case with psudomeningeocele with regard to clinical outcome, the literature is controversial. Cammisa et al., and Wang et al., reported that no long-term sequelae in cases with incidental dural tear $[2,8]$. Saxler and colleagues reported that poorer outcomes in cases with incidental dural tear, [15] in our study there was no significant squealae on the outcome.

\section{Conclusions:}

Risk factors for unintended durotomy were female sex, older age, degenerative spondylolisthesis, and younger surgeons with short experience. 


\section{References}

1- BAKER G.A., CIZIK A.M., BRANSFORD R.J., et al.: Risk factors for unintended durotomyduring spine surgery: A multivariate analysis. Spine J., 12: 121-6, 2012.

2- CAMMISA F.P., G[RARDI F.P., SANGANI P.K., et al.: Incidental durotomy in spine surgery. Spine, 25: 2663-7, 2000.

3- GUERIN P., El-FEGOUN A.B., OBEID I., Gille O., et al.: Incidental durotomy during spine surgery: Incidence, management and complications. A retrospective review. Injury, 43: 397-401, 2012.

4- KHAN M.H., RIHN J., STEELE G., DAVIS R., et al.: Post-operative management protocol for incidental dural tears during degenerative lumbar spine surgery: A review of 3,183 consecutive degenerative lumbar cases. Spine (Phila Pa 1976), 31: 2609-13, 2006.

5- LOTAN R., AL-RASHDI A., YEE A., et al.: Clinical featuresof conjoined lumbosacral nerve roots versus lumbar intervertebraldisc herniations. Eur. Spine J., 19: 1094-8, 2010

6- KALEVSKI S.K., PEEV N.A. and HARITONOV D.G.: Incidental dural tearsin lumbar decompressive surgery: Incidence, causes, treatment,results. Asian. J. Neurosurg., 5: 54-9, 2010

7- MORGAN-HOUGH C.V., JONES P.W. and EISENSTEIN S.M.: Primary andrevision lumbar discectomy. A 16-year review from one centre. J. Bone. Joint. Surg. Br., 85: 8714, 2003.
8- WANG J.C., BOHLMAN H.H. and RIEW K.D.: Dural tears secondaryto operations on the lumbar spine. Management and results fter a two-year-minimum follow-up of eighty-eight patients. J. Bone. Joint. Surg. Am., 80: 1728-32, 1998

9- WILLIAMS B.J., SANSUR C.A., SMITH J.S., et al.: Incidence of unintended durotomyin spine surgery based on 108, 478 cases. Neurosurgery, 68: 117-24, 2011.

10- SIN A.H., CALDITO G., SMITH D., et al.: Predictive factors for dural tear and cerebrospinal fluidleakage in patients undergoing lumbar surgery. J. Neurosurg. Spine, 5: 224-7, 2006.

11- BOSACCO S.J., GARDNER M.J. and GUILLE J.T.: Evaluation and treatmentof dural tears in lumbar spine surgery: A review. Clin. Orthop. Relat. Res., 389: 23847, 2001.

12- EPSTEIN N.E.: The frequency and etiology of intraoperative duraltears in 110 predominantly geriatric patients undergoingmultilevel laminectomy with noninstrumented fusions. J. Spinal. Disord. Tech., 20: 380-6, 2007.

13- TAFAZAL S.I. and SELL P.J.: Incidental durotomy in lumbar spine surgery: Incidence and management. Eur. Spine. J., 14: 287-90, 2005.

14- YOSSI S., KEVIN C. BAKER, et al.: Predisposing factors for dural tear in patients undergoing lumbar spine surgery. J. Neurosurg. Spine, 22: 483-6, 2015.

15- SAXLER G., KRAMER J., BARDEN B., KURT A., et al.: The long-term clinical sequelae of incidental durotomy in lumbar disc surgery. Spine, 30: 2298-302, 2005.

\section{العومل التى تعرض آلام الجافية للقطع آثناء عملية

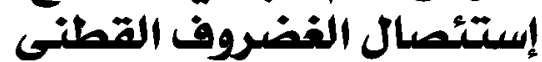

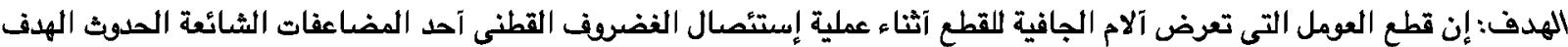

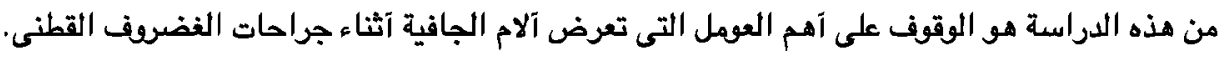

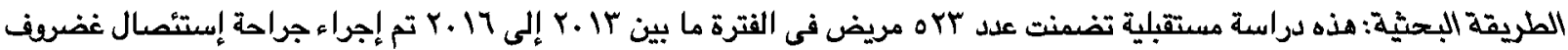

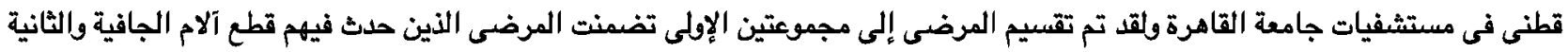

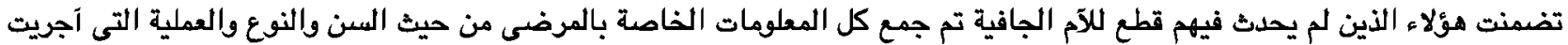

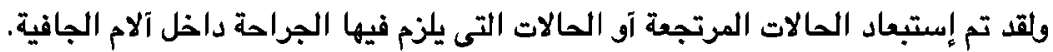

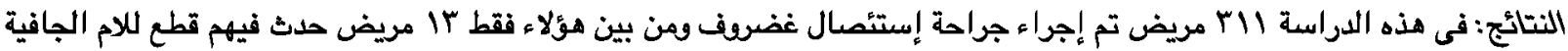

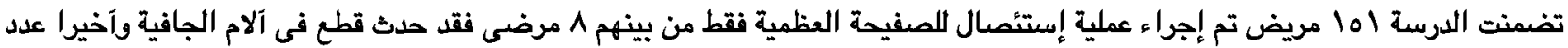

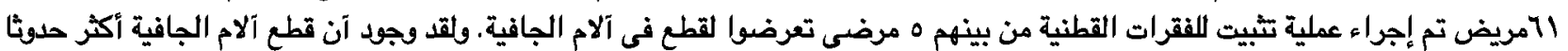

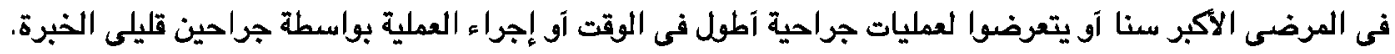

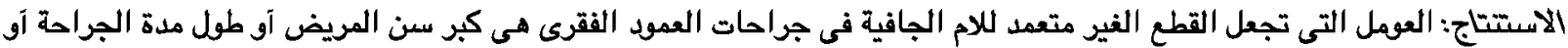

$$
\begin{aligned}
& \text { آن يتم إجراء الجراحة بواسطة الجراحين الصغار قليلى الفيلى الخبرة. }
\end{aligned}
$$

